\title{
Characterization of Adulteration of "Espinheira Santa" (Maytenus ilicifolia and Maytenus aquifolium, Celastraceae) Hydroalcoholic Extracts with Sorocea bomplandii (Moraceae) by High-Performance Thin Layer Chromatography
}

\author{
Janete H. Y. Vilegas, ${ }^{1}$ Fernando M. Lanças, ${ }^{1 *}$ Jean-Noël Wauters ${ }^{2}$ and Luc Angenot ${ }^{2}$ \\ ${ }^{1}$ Universidade de São Paulo, Instituto de Química de Sâo Carlos, Caixa Postal 780, 13560-970, São Carlos, SP, Brazil \\ ${ }^{2}$ Université de Liège, Institut de Pharmacie, avenue de l'Hôpital 1, B36, B-4000, Liège, Belgium
}

\begin{abstract}
A high-performance thin layer chromatographic (HPTLC) procedure for the characterization of adulteration of "espinheira santa" (Maytenus ilicifolia and Maytenus aquifolium, Celastraceae) with Sorocea bomplandii (Moraceae), by monitoring their flavonoid content with the aid of diphenylboric acid-2aminoethylester-polyethylene glycol 400 reagent, is presented. HPTLC data showed the predominance of highly glycosylated quercetin and kaempferol derivatives. The derivatized flavonoids were shown to be the best markers for distinguishing between authentic and adulterated drug samples, with several advantages over triterpene analysis. (C) 1998 John Wiley \& Sons, Ltd.
\end{abstract}

Phytochem. Anal. 9, 263-266, 1998

Keywords: High-performance thin layer chromatography (HPTLC); densitometry; Maytenus ilicifolia; Maytenus aquifolium; flavonoids; diphenylboric acid-2-aminoethylester-PEG 400 reagent.

\section{INTRODUCTION}

"Espinheira santa" (Maytenus ilicifolia Martius and M. aquifolium Martius, Celastraceae) leaves are utilized in Brazilian health programs as alternatives to the more expensive synthetic anti-ulcer drugs, because of their proven activity against gastritis and gastric ulcers (Carlini, 1988). The pharmacological action of these drugs was shown to be related to the presence of both triterpenes and phenolic compounds (Oliveira et al., 1992; Pereira et al., 1992). The most abundant triterpenes in these Maytenus leaves are friedelin and friedelan-3-ol, which have been shown to be useful as markers for the characterization of authenticity of the crude drug plant by high resolution gas chromatography (HRGC; Vilegas et al., 1994, 1995). Although the presence of flavonoids, catechins and tannins was reported in the polar extracts (Oliveira et al., 1992), only a conventional thin layer chromatographic (TLC) procedure has been proposed for the characterization of "espinheira santa" hydroalcoholic extracts (Petrovick et al., 1991).

HPTLC is an instrumental technique, which represents

* Correspondence to: F. M. Lanças, Universidade de São Paulo, Instituto de Química de São Carlos, Caixa Postal 780, 13560-970, Sāo Carlos, SP, Brazil, flancas@iqsc.sc.usp.br.

Contract/grant sponsor: FAPESP, Brazil

Contract/grant sponsor: CNPq, Brazil.

Contract/grant sponsor: FNRS, Belgium. an improvement over conventional TLC by using special plates and instrumental resources for sample application, together with quantitative evaluation of separations with the aid of densitometry. In the quantitative analysis of active compounds in a crude plant extract, the utilization of specific derivatization reagents shows several advantages over high performance liquid chromatography (HPLC) in plant drug analysis (Jork et al., 1990, 1994; Szepesi and Nyiredy, 1992; Poukens-Renwart, 1993).

In this communication, we report on the use of HPTLC-densitometry for the characterization of adulterations of "espinheira santa", by analysis of the flavonoids from hydroalcoholic extracts of authentic Maytenus samples and its adulterant, Sorocea bomplandii (Baill.) Buerger Lang \& Boer (Moraceae), after derivatization with diphenylboric acid-2-aminoethylesterpolyethylene glycol (PEG) 400 reagent.

\section{EXPERIMENTAL}

Plant material. Authentic samples of leaves of "espinheira santa" (Maytenus ilicifolia M. and M. aquifolium M.) were furnished by Ana Maria Soares Pereira (UNAERP, Ribeirão Preto, SP, Brazil). The plant material was dried $\left(40^{\circ} \mathrm{C}\right.$, forced ventilation, $\left.3 \mathrm{~d}\right)$, ground and sieved. Only plant material between 0.210 and $0.350 \mathrm{~mm}$ was utilized for extraction. 
Authentic samples of leaves of Sorocea bomplandii (Baill.) Buerger Lang \& Boer were collected by Antonio Carlos Cervi (UFPr, Brazil) in Jaguariava, PR, Brazil (voucher number UPCB 20263). The plant material was dried, ground and sieved, as described above.

Preparation of the samples. A reference solution of rutin was prepared by dissolving rutin (Sigma, St Louis, MO, USA) in methanol $(1.0 \mathrm{mg} / \mathrm{mL})$. Friedelin was purified from $M$. aquifolium and its identity confirmed from its melting point and ${ }^{1} \mathrm{H}$ and ${ }^{13} \mathrm{C}$ nuclear magnetic resonance (NMR) spectra: a reference solution in chloroform $(1.0 \mathrm{mg} / \mathrm{mL})$, was utilized for terpenoid analysis.

Ground plant material $(0.3 \mathrm{~g})$ was extracted with methanol $(5 \mathrm{~mL})$ for $10 \mathrm{~min}$, at $60^{\circ} \mathrm{C}$ under agitation, followed by filtration over $500 \mathrm{mg}$ anhydrous sodium sulphate. The methanolic extract was evaporated to dryness at room temperature and the residue was suspended in $0.25 \mathrm{~mL}$ methanol (analytical grade; Merck; Darmstadt, Germany) and filtered (Millipore membrane; $0.45 \mu \mathrm{m}$ HVLP; Waters, Milford, MA, USA), for HPTLC analysis.

In order to obtain a terpenoid fraction, plant material (1 g) was extracted with boiling hexane under reflux $(50 \mathrm{~mL})$ for $5 \mathrm{~min}$. After cooling, activated charcoal $(500 \mathrm{mg})$ was added and the extract was reheated to boiling and filtered. The mixture was evaporated to dryness at room temperature, and the residue was suspended in $1.0 \mathrm{~mL}$ chloroform (analytical grade; Merck) and filtered using a $0.45 \mu \mathrm{m}$ HVLP membrane prior to HPTLC analysis. The slightly different procedure adopted for the qualitative HRGC-flame ionisation detection (FID) and mass spectral (MS) analysis of "espinheira santa" has been previously described (Vilegas et al., 1994).

Solutions containing the flavonoid fraction were prepared by extracting ground leaves $(3 \mathrm{~g})$ with boiling methanol $(30 \mathrm{~mL})$ for $30 \mathrm{~min}$ under agitation, followed by filtration. The methanolic extract was mixed with an equal volume of distilled water, and the resulting solution was evaporated under vacuum until the chloropylls precipitated. The resulting supernatant was eluted through a glass column $(60 \times 1 \mathrm{~cm}$ i.d. $)$ containing $45 \mathrm{~mL}$ of Amberlite XAD-2 (Aldrich, Milwaukee, WI, USA), for adsorption (enrichment) of the flavonoids. The adsorbent was washed with water and the flavonoids were desorbed with methanol $(50 \mathrm{~mL})$. The solvent was evaporated under vacuum at a temperature of less than $60^{\circ} \mathrm{C}$. An aliquot $(10 \mathrm{mg})$ of the residue was dissolved in methanol $(1 \mathrm{~mL})$ and filtered $(0.45 \mu \mathrm{m}$ HVLP membrane $)$ prior to HPTLC analysis.

HPTLC analysis of samples. Chromatographic analyses of the hydroalcoholic extracts and flavonoid fractions were performed on $10 \times 10 \mathrm{~cm}$ silica gel 60 F254 HPTLC plates (Merck; Art. 5642). Aliquots ( $3 \mu \mathrm{L}$ each) of each sample and of the standard solution were applied to the plates as bands by means of a Desaga (Heildelberg, Germany) AS30 TLC applicator. The width of the bands was $5 \mathrm{~mm}$ and the distance between the middle of the bands was $10 \mathrm{~mm}$, the step volume was $1 \mu \mathrm{L}$, and the rate of application was $15 \mathrm{~s} / \mu \mathrm{L}$; the break between applications was $15 \mathrm{~s}$. When the spots were dry, separation was performed in an unsaturated chamber at room temperature using ethyl acetate: formic acid: water $(6: 1: 1, \mathrm{v} / \mathrm{v})$ as the mobile phase (Brasseur and Angenot, 1988; Brasseur et al., 1988). The development distance was $70 \mathrm{~mm}$ (development time approximately $30 \mathrm{~min}$ ). After development, the plates were dried at $90^{\circ} \mathrm{C}$ for $15 \mathrm{~min}$ on a hot plate, and derivatization was carried out by immersion of the plates in a solution of diphenylboric acid-2aminoethylester $(100 \mathrm{mg})$ and PEG $400(500 \mathrm{mg})$ in methanol (10 mL) (Brasseur and Angenot, 1988).

The analyses of terpenoid extracts were carried out using the conditions described for the analysis of flavonoids and hydroalcoholic extracts, except for the following parameters: sample solution $-2 \mu \mathrm{L}$; rate of application $-10 \mathrm{~s} / \mu \mathrm{L}$; break between applications -15 s. The separation was performed in a chamber saturated for $30 \mathrm{~min}$, at room temperature, using hexane:ethyl acetate $(92: 8, \mathrm{v} / \mathrm{v})$ as the mobile phase. The development distance was $70 \mathrm{~mm}$. After development, plates were dried in a fume cupboard at room temperature for approximately $10 \mathrm{~min}$, and derivatized by immersion in a solution of concentrated sulphuric acid $(10 \mathrm{~mL})$ in methanol $(5 \mathrm{~mL})$ and water $(85 \mathrm{~mL})$ (Jork et al., 1990), followed by heating at $105^{\circ} \mathrm{C}$ for $5 \mathrm{~min}$ on a hot plate.

Densitometric evaluation of samples. Plates containing hydroalcoholic extracts and flavonoid fractions were scanned $3 \mathrm{~h}$ after derivatization, using a CD60 densitometer (Desaga) operated by software running on a personal computer under the following conditions: scanning mode - re-emission-fluorescence ( $\mathrm{Hg}$ lamp); measurement wavelength -300 or $400 \mathrm{~nm}$ (emission cut-off filter $450 \mathrm{~nm}$ ); slit width $-0.2 \mathrm{~mm}$; slit height $6.0 \mathrm{~mm}$; spot optimization mode; resolution $0.100 \mathrm{~mm}$; number of measurements per position -16 ; signal factor - 20. Peak area measurement was utilized.

Plates containing triterpenes were scanned immediately after heating. The conditions were as described for the analysis of flavonoids and hydroalcoholic extracts, except for the following parameters: scanning mode re-emission-extinction ( $\mathrm{D}$ and $\mathrm{T}$ lamp); measurement wavelength $-550 \mathrm{~nm}$; slit height $-8.0 \mathrm{~mm}$; number of measurements per position -8 ; signal factor -50 .

Photographic record. After $3 \mathrm{~h}$ derivatization, flavonoids which had been separated on HPTLC were photographed utilizing a VD40 VideoDocumentation System (Desaga) at an excitation wavelength of $366 \mathrm{~nm}$ with the data being analysed using Doclt (Desaga) software running under Windows on a personal computer.

\section{RESULTS AND DISCUSSION}

\section{Analysis of terpenoids}

The initial experiments were performed with hexane extracts (terpenoid fraction), since this fraction had been shown to be valuable for the analysis of plant material by HRGC (Vilegas et al., 1994). However, the HPTLC fingerprints of $M$. ilicifolia and $M$. aquifolium (authentic "espinheira santa") and its main adulterant (S. bomplandii) were not sufficiently different as to allow the unequivocal identification of the plant material: all three samples showed a high content of triterpenoids with $R_{\mathrm{f}}$ values very close to each other. Furthermore, the 
(a)



(b)

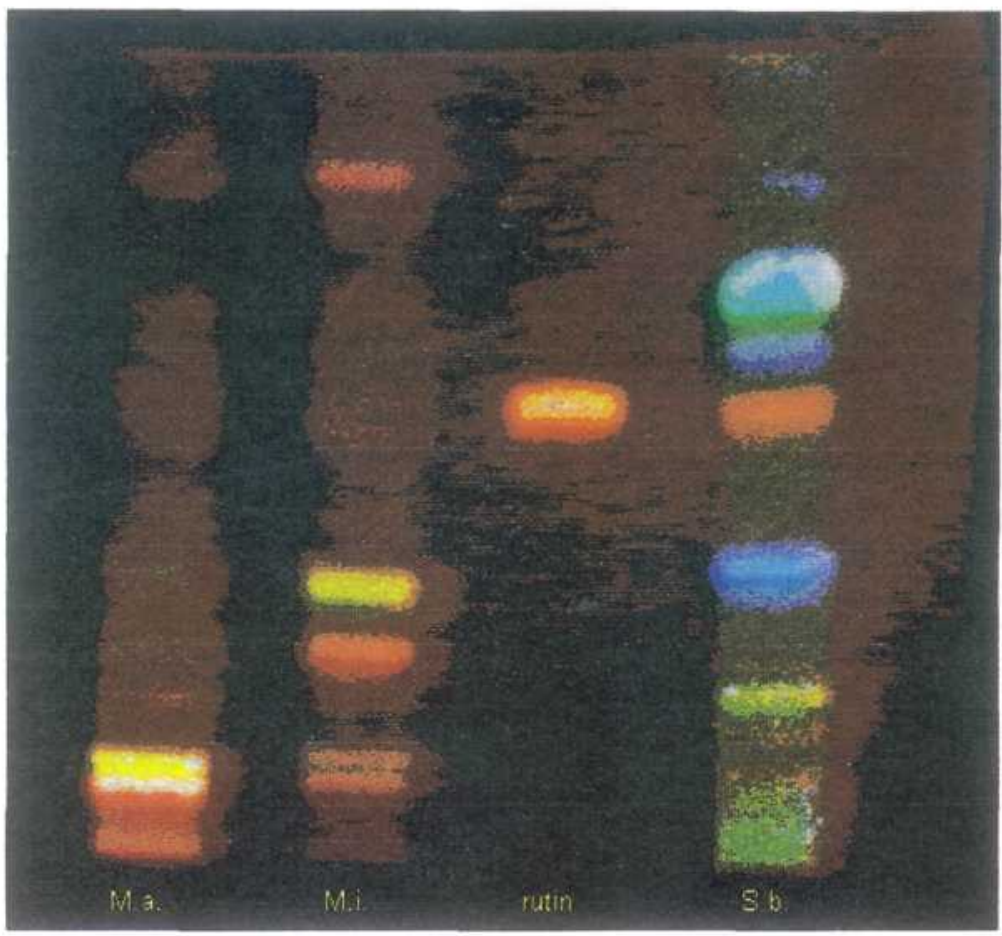

Plate 1. Photographic records of HPTLC plates treated with diphenylboric acid-2-aminoethylester-PEG 400 reagent $\left(\lambda_{\text {excitation }}=366 \mathrm{~nm}\right)$ following analysis of (a) crude methanolic extracts, and (b) flavonoid fractions of the samples: Maytenus aquifolium (lane M.a.); Maytenus ilicifolia (lane M.i.); Sorocea bomplandii (adulterant) (lane S.b.) and rutin (standard). For chromatographic protocol see Experimental section. 


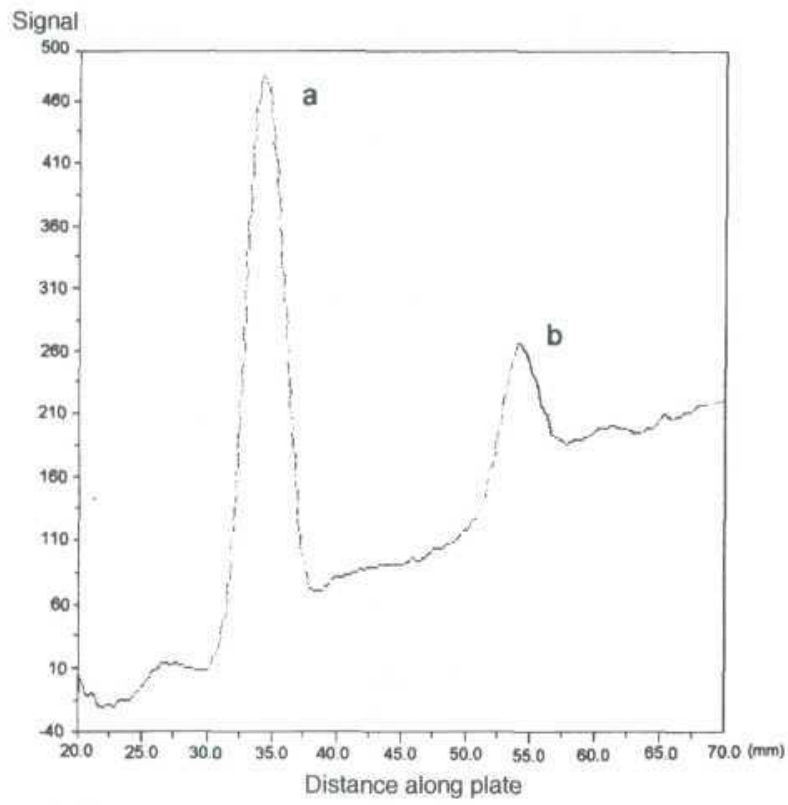

Figure 1. Densitometric scan (absorbance at $550 \mathrm{~nm}$ ) of the HPTLC separation of an hexane extract (triterpene fraction) of "espinheira santa", after derivatization with methanolic $10 \%$ sulphuric acid reagent. Peak identification: (a) friedelin; (b) friedelan-3-ol. (For chromatographic protocol see Experimental section).

densitometric evaluation of authentic samples of friedelin and friedelan-3-ol (the main constituents of the hexane extracts from both species of Maytenus) indicated an absence of linearity and reproducibility, particularly for friedelin, using various HPTLC elution systems and visualization reagents for terpenoids (Jork et al., 1990; Wagner et al., 1984). The best results were obtained using methanolic sulphuric acid reagent (Fig. 1), and here the analytical problems arose from the background colour, which caused an elevation of the baseline along the plate distance owing to the absorption in the visible region of the spectra. This problem was also found when vanillin:sulphuric acid or anisaldehyde:sulphuric acid reagents (often employed to reveal terpenoids) were used. Thus the utilization of triterpenes as markers in HPTLC analysis had to be discarded.

\section{Analysis of crude hydromethanolic extracts}

The direct HPTLC analysis of the flavonoid fractions was shown to be very useful. Plate 1(a) shows the photographic record of the HPTLC analysis of the crude methanolic extract from reference samples, and this allows clear differentiation between the authentic and false "espinheira santa" samples. The main differences observed between the crude methanolic extract and the prepared flavonoid fraction [Plate 1(b)] appears in the minor compounds, mainly from $S$. bomplandii. The solvent system utilized for the HPTLC method showed no interference from the chlorophyll (which eluted at the solvent front, see the dark red spot at the top of the $S$. bomplandii lane). In short, for a fast and non-quantitative screening for the authenticity of a commercial "espinheira santa" sample, analysis of the crude methanolic extract is a cheap and fast choice.
Our experiments indicated that the utilization of conventional, commercial, pre-coated TLC plates (e.g., DC Silicagel 60 F254; Merck; Art. 5735) is a good choice for a simple qualitative analysis, employing the same chromatographic conditions as described here for the HPTLC analysis of flavonoids. For a preliminary quality control analysis, this procedure is a cheaper and faster alternative to HRGC analysis of triterpenes in hydroalcoholic extracts of Maytenus (Vilegas et al., 1995). This last method, despite its efficiency for the characterization of adulterations, is not yet a routine tool, in contrast with conventional TLC. Finally, owing to the high content of chlorophylls, the HPLC analysis of crude extracts of Maytenus and Sorocea is not possible using conventional chromatographic conditions (i.e. C-18, reverse phase).

\section{Analysis of flavonoids}

Crude extracts of both $M$. ilicifolia and $M$. aquifolium showed low amounts of flavonoids and so an enrichment step using solid-phase (XAD-2) extraction of the flavonoids was adopted. The flavonoids from Maytenus $s p p$. are very polar, probably triglycosylated, since their $R_{\mathrm{f}}$ values were comparable with those of reference samples of triglycosylated flavonoids obtained from Strychnos spp. (Brasseur and Angenot, 1988). All of the TLC data are in agreement with preliminary NMR and MS data obtained from a phytochemical investigation of both Maytenus spp. (Sannomiya et al., 1998). The flavonoids from Maytenus spp. exhibited strong orange or green fluorescence under long-wave UV after derivatization. This indicated a predominance of quercetin and kaempferol heterosides, respectively, since the reagent utilized allows the distinction of these different classes of flavonols (Brasseur et al., 1988).

In contrast, the flavonoids from $S$. bomplandii were more diverse: the solid phase extraction procedure furnished a fraction containing mainly flavonoids, ranging from compounds with $R_{\mathrm{f}}$ values higher than rutin (utilized as the reference HPTLC compound) with blue fluorescence (suggesting the presence of caffeic acid and/or coumarin derivatives), to flavonoids with low $R_{\mathrm{f}}$ values, but not as polar as those found in Maytenus spp., and with a predominance of kaempferol derivatives (green fluorescence under long-wave UV after derivatization) (Brasseur and Angenot, 1988). Plate 1(b) shows the photographic record of an HPTLC analysis of the flavonoid fraction of reference samples, and exemplifies a further advantage of HPTLC over HPLC, namely the possibility of a comparative analysis of several samples in one chromatographic run.

\section{CONCLUSIONS}

The HPTLC technique proved to be useful for distinguishing hydroalcoholic extracts originating from authentic and false "espinheira santa" samples. This medicinal plant is often found on the Brazilian market in an extract form, and a quality control method for the analysis of such preparations is required. The successful utilization of diphenylboric acid-2-aminoethyl esterPEG 400 reagent, indicates that quantitative analysis of 
the flavonoids from Maytenus spp. can be performed, since this reagent has been utilized in quantitative HPTLC densitometric evaluation of flavonoids from other medicinal plants, such as spiraeoside in Filipendula ulmaria L. flowers (Poukens-Renwart et al., 1992). Therefore, the next step in the development of a quality control procedure for "espinheira santa" could be the validation of HPTLC methodology for the quantitative analysis of the active polar compounds, after isolating and determining the full chemical structure of these substances.

\section{Acknowledgements}

The authors wish to thank FAPESP and CNPq (Brazil), and FNRS (Belgium) for financial aid and fellowships.

\section{REFERENCES}

Brasseur, T. and Angenot, L. (1988). Six flavonol glycosides from leaves of Strychnos variabilis. Phytochemistry 27, $1487-1490$.

Brasseur, T., Wauters, J.-N. and Angenot, L. (1988). Dosage densitométrique d'hétérosides de la quercétine dans les extraits végétaux. J. Chromatogr. 437, 260-264.

Carlini, E. L. A. (1988). Estudo de Açāo Antiúlcera Gástrica de Plantas Medicinais Brasileiras: Maytenus ilicifolia (Espinheira Santa) e Outras. CEME/AFIP, Brasília.

Jork, H., Funk, W., Fischer, W. and Wimmer, H. (1990). Thin Layer Chromatography: Reagents and Detection Methods. Vol. 1A. VCH, Weinheim.

Jork, H., Funk, W., Fischer, W. and Wimmer, H. (1994). Thin Layer Chromatography: Reagents and Detection methods. Vol 1B. VCH, Weinheim.

Oliveira, A. B., Zhao-Hua, W., Gontijo, C., Récio, R. A., Almeida, V. L., Ferreira, P. M. and Vieira, M. A. R. (1992). Produtos nuturais com atividade em ulcera gastrica. XII Simp. Plantas Medicinais Brasil. Anais, p. 55, UFPR, Curitiba.

Pereira, A. M. S., Rodrigues, D. C., Cerdeira, R. M. de M. and França, S. de C. (1992). Isolamento de metabólitos de Maytenus associados á ação anti-úlcera gástrica. XII Simp. Plantas Medicinais Brasil. Anais p. 072, UFPR, Curitiba.

Petrovick, P. R., Jacob, M., Gaudy, D. and Lopes, C. H. C. (1991). Extratos secos por nebulização: avaliaçăo comercial de nebulizados de Maytenus ilicifolia Martius ex Reiss. - Celastraceae. Cad. Far. (Porto Alegre) 7 (Suppl.), L52-L54.
Poukens-Renwart, P. (1993). Interêt de la chromatographie planaire dans le contrôle de la composition chimique de medicaments d'origine naturelle: étude de cinq plantes á reputation anti-rhumatismale (Filipendia ulmaria L., Fraxinus excelsior L., Harpagophytum procumbens DC, Ribes nigrum L., Salix alba L.), PhD Thesis, Université de Liège, Belgium.

Poukens-Renwart, P., Tits, M., Wauters, J.-N. and Angenot, L. (1992). Densitometric evaluation of spiraeoside after derivatization in flowers of Filipendula ulmaria (L.) Maxim. J. Pharm. Biomed. Anal. 10, 1085-1088.

Sannomiya, M., Vilegas, W., Rastrelli, L. and Pizza, C. (1998). A flavonoid glycoside from Maytenus aquifolium. Phytochemistry 49, 237-239.

Szepesi, G. and Nyiredy, S. (1992). Planar chromatography: current status and future perspectives in pharmaceutical analysis. I. Applicability, quantitation and validation. $J$. Pharm. Biomed. Anal. 10, 1007-1015.

Vilegas, J. H. Y., Lanças, F. M. and Cervi, A. C. (1994). High resolution gas chromatography analysis of "espinheira santa" (Maytenus ilicifolia and M. aquifolium): analysis of crude drug adulterations. Phytother. Res. 8, 241-244.

Vilegas, J. H. Y., Lanças, F. M. and Antoniosi Filho, N. R. (1995). High temperature capillary GC analysis of phytopreparations of "espinheira santa" (Maytenus ilicifolia M. and Maytenus aquifolium M. - Celastraceae), a Brazilian antiulcer plant. Chromatographia 40, 341-344.

Wagner, H., Bladt, S. and Zgainski, E. M. (1984) Plant Drug Analysis. Springer, Berlin 